$$
\text { NASA TM - 88261 }
$$

NASA Technical Memorandum 88261

NASA-TM-88261

19860016869

\title{
Validation of a New Flying Quality Criterion for the Landing Task
}

Donald T. Berry and Shahan K. Sarrafian

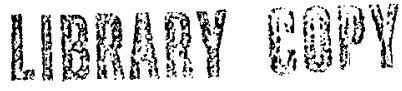

iug?

IANGLEY KESEARCH CENTEF

LIBRARY, NASA

HGMPTON, YIROMNAA 
NASA Technical Memorandum 88261

\section{Validation of a New Flying Quality Criterion for the Landing Task}

Donald T. Berry and Shahan K. Sarrafian

Ames Research Center, Dryden Flight Research Facility, Edwards, California

\section{N/Sก}

National Aeronautics and

Space Administration

Ames Research Center

Dryden Flight Research Facility

Edwards, California 93523-5000 


\author{
Donald T. Berry* and Shahan K. Sarrafian** \\ NASA Ames Research Center \\ Dryden Flight Research Facility \\ Edwards, California
}

\section{Abstract}

A strong correlation has been found to exist between flightpath angle peak overshoot and pilot ratings for the landing task. The use of flightpath overshoot as a flying quality metric for landing is validated by correlation with four different in-flight simulation programs and a ground simulation study. Configurations tested were primarily mediumweight generic transports. As a result of good correlation with this extensive data base, criterion boundaries are proposed for landing based on the flightpath peak overshoot metric.

\section{Nomenclature}

NLR National Aerospace Laboratory (National Lucht - en Ruimtevaartlaboratorium, Netherlands)

PR

pilot rating

PRCS

pitch-rate control system

TIF'S

$$
\text { total in-flight simulator }
$$

\section{Introduction}

In recent years, the flying qualities of advanced aircraft have been the subject of some controversy. These vehicles are heavily augmented and, in most cases, have pitch-rate command systems for the approach and landing regime. This results in some characteristics that are different from those of classical aircraft of the past. For example, conventional aircraft tend to settle into the ground after the flare because of the speed loss accompanying the pullup. This speed loss results in a loss of lift, leading to a downward vertical velocity which tends to increase angle of attack. This angle-of-attack increase, in turn, tends to counteract the $1 \mathrm{ift}$ loss and rate of sink. In a conventional aircraft, the increase in angle of attack also results in a nose-down pitching moment due to its static stability. This mornent tends to cause the aircraft to nose over and further increase its rate of descent. However, the pilot uses aft stick force to keep the nose from dropping and the aircraft from settling down too quickly. As a result, pilots are used to varying aft stick force to control the rate of sink during touchdown.

On the other hand, aircraft with pitch-rate command systems resist the tendency of the aircraft to nose down and settle because they automatically hold the pitch rate constant. This

*Aerospace Engineer, Flight Operations and

Research virectorate. Associate Fellow, AIAA.

**Aerospace Engineer, Flight Operations and

Research Uirectorate. Member, AIAA. results in a greatly reduced settling tendency, and no aft stick force is required to hold the nose up. In some cases, a push force may be required to make the aircraft touch down.

The characteristics of conventional and pitchrate command aircraft are illustrated in Figs. 1 and 2 , which are time histories of aircraft response to a 5-sec boxcar or block input. The block input is convenient analytically and also represents a reasonable pilot technique: pull back on the stick an amount that provides a comfortable pitch rate and hold it until a desired rate of descent or flightpath angle is attained, then neutralize the controls.

Figure 1 shows a conventional aircraft response. After an initial transient, the aircraft tends to pitch up at a constant rate, and pitch attitude increases until the controls are neutralized. Flightpath angle also increases. When the controls are neutralized, the aircraft noses down and flightpath angle decreases. A typical pitch-rate command system response (Fig. 2) looks similiar initially; however, when the controls are neutralized, the aircraft holds its pitch attitude because, in effect, a zero pitch rate is being commanded. Also, flightpath angle reduces considerably more slowly than for the conventional aircraft.

Pilots newly introduced to pitch-rate command flight control systems have a strong tendency to float or balloon on landing. Some analysts believe this is only a familiarization problem that can be overcome with modest training. 0thers think that these systems have basic flying quality deficiencies and need to be designed to have characteristics more like conventional aircraft.

To expand the data base available on this subject, the Dryden Flight Research Facility of NASA Ames Research Center (Ames-Dryden), together with Langley Research Center, sponsored an in-flight simulation program. Tests were conducted on the U.S. Air Force/Calspan total in-flight simulator (TIFS). The program investigated the influence of such factors as pitch-rate command systems, leadlag prefilters, washout, lift curve slope, and static stability on flying qualities in the landing task for a generic transport aircraft. This program made it possible to extend the range of parameters available from flight experience to future designs while maintaining the visual, motion, and stress factors of actual flight.

The results of the TIFS pitch-rate control systems (PRCS) programl showed good correlation with a flightpath overshoot parameter. 2 This paper extends the correlation of the flightpath overshoot parameter to data from Refs. 3 and 4 and also makes a preliminary comparison with data from two recent TIFS programs. 
Discussion

\section{Data Correlation}

In Ref. 2, pitch attitude and flightpath angle were investigated as pilot-centered variables in the time domain that might be metrics for flying qualities in the landing task. Time domain criteria have much appeal because data can be anatyzed directly from simulator or flight time histories. They are especially adaptable to specification and evaluation criterion requirements. They also provide flexible guidelines for flight control system design.

Reference 1 found good correlation with a time domain criterion based on angle of attack and normal acceleration at the pilot location. However, this criterion depended on a somewhat complex conbination of initial angle-of-attack slope, first normal acceleration peak, second normal acceleration peak, and a weighted value of the time to reach steady-state angle of attack. The primary factors in the correlation were the angle-ofattack terms. However, the angle of attack is not visible to the pilot, and it is difficult to perceive how this influences the pilot's impression of flying qualities. Reference 2 investigated two pilot-centered time domain variables - pitch attitude and flightpath angle. Excellent correlation was found between flightpath angle peak overshoot and the pilot rating (PR) data of Ref. 1 .

Fliyhtpath angle response was analyzed 2 using the parameters illustrated in Fig. 3. The value at control release and the peak value were used. The reference input was a 5-sec block, as used in Ref. 1 , as this is a reasonable pilot command for a flare maneuver. Figure 4 shows the correlation of this parameter with the pilot rating results for the TIFS PRCS program using flightpath angle measured at the pilot location. The correlation is excellent; 86 percent of the data are within $\pm 1.5 \mathrm{PR}$, and 95 percent are within $\pm 2.0 \mathrm{PR}$.

This is excellent correlation, especially when one considers the ease of measuring and applying the metric. The reason for the good correlation is believed to be the fact that it is pilotcentered. The flightpath overshoot is an indication of the predictability of the flightpath response. This is very important in the landing task. If the aircraft acquires (with little or no overshoot) the flightpath angle that the pilot sees on neutralizing the controls, he can readily predict the response. On the other hand, if the aircraft significantly overshoots the flightpath angle that the pilot sees when he releases the controls, it is difficult for him to anticipate the response.

To test further the validity of this metric, data for shuttle-like configurations from the large aircraft program 3 and data without excessive pitch-rate overshoot from the National Aerospace Laboratory (Nationaal Lucht-en Ruintevaartlaboratorium, NLR, Netherlands) program $^{4}$ were analyzed with the flightpath peak overshoot parameter. These proyrams addressed generic transports. The NLR program consisted of a ground simulation phase and a TIFS phase. Figure 5 shows these data together with that from the PRCS program. NLR ground simulator and TIFS data compare favorably with the PRCS data and extend the data to larger values of flightpath angle overshoot. The horizontal scale in Fig. 5 is expanded (as compared with that in Fig. 4) to accommodate the larger values of flightpath angle overshoot. In addition, the fairing of the data has been modified slightly to provide the best consistency with all the data. Horizontal fairings at the low and high ends of the data range somewhat improve the correlations. This is consistent with general past experience; pilot ratings become insensitive to changes as the extremes of the rating scale are approached. Correlation with all these data is still very good; 93 percent of the data are within a $\pm 2.0-P R$ scatter band and 77 percent are within a $\pm 1.5-P R$ band. These results give additional credence to the validity of flightpath overshoot as a criterion for flying qualities in the landing task.

Two recent TIFS programs are also of interest. An in-flight simulation of proposed modifications to the shuttle flight control system for landing was conducted in spring 1985 and was jointly sponsored by Ames-Dryden and Johnson Space Center. A follow-on to the PRCS study of Ref. 1 was conducted in winter 1985-1986 and was sponsored by Ames-Dryden and Langley Research Center. These data were examined to determine if they might confirm or deny the validity of the flightpath peak overshoot metric. The use of data from these two programs must be considered tentative, however. The shuttle simulation landing task was different from the conventional landings used in all the other studies and includes a decelerating approach. The PRCS follow-on results are preliminary and are still being analyzed. Figure 6 presents these data added to that from Fig. 5.

The TIFS shuttle results cover a narrow range of flightpath overshoot, and the trend with this metric is obscured by normal scatter. However, these data are consistent with results of the previous studies. They are within the scatter band and tend to follow the same slope as the other data.

The TIFS shuttle data are on the high side of the scatter band, which may be due to the shuttle training of the pilots used in this study. Nevertheless, the flightpath angle peak overshoot metric does predict that the overall improvement resulting from these particular control system modifications would be small, which indeed was the case. However, these configurations did bring out many important aspects of shuttle dynamics and pilot technique beyond the scope of this paper. These aspects are reported in Ref. 5 .

The PRCS follow-on data, although covering a wider range of flightpath angle peak overshoot than the shuttle data, are primarily in the region where the pilot is relatively insensitive to variations in the metric. Nevertheless, the scatter band of these data is consistent with the established trends. Therefore, it is concluded that these recent data support the previously established trends of flightpath angle peak overshoot. In fact, the percentage of points within the scatter bands is essentially the same in Figs. 5 and 6 . 
Monotonic Stick Force

Reference 1 indicates that the aft stick requirement during a typical landing of a conventional aircraft is important for good flying qualities. This aft stick behavior (designated as monotonic in Ref. 1) is a consequence of the strong flightpath settling tendency associated with the speed loss in the flare and the static stabllity of conventional aircraft, as discussed in the Introduction. However, as noted in Ref. 2, modifications to the control system that reduced the flightpath angle peak overshoot improved pilot ratings whether or not the settling tendency and associated monotonic stick forces were affected. For example, lead-lag prefilters as well as washout filters reduce the flightpath overshoot when applied to a typical rate command system atrcraft. However, lead-lag prefilters did not increase the flightpath settling tendency, whereas washout filters did. This is illustrated in Figs. $7(a)$ and $7(b)$. Hence, the question arises as to whether the improvements are the result of monotonic stick forces, reductions in flightpath overshoot, or both. Some insight into this question can be provided by Fig. 8 in which the solid symbols indicate all data points that have significant flightpath settling. It can be seen that aircraft with strong settling tendencies always have low values of flightpath overshoot. This guarantees that aircraft with "conventional" response will have good flying qualities with regard to flightpath response. However, numerous data poirits (open symbols, Fig. 8) also populate the low flightpath overshoot region which indicates that these good flying qualities are also possible without monotonic stick forces. Except for their low flightpath overshoot, a preference for the conventional responses does not seem to be indicated.

\section{Proposed Criteria}

Based on the consistency of the flightpath peak overshoot metric with 62 data points from varied sources, a criterion is proposed. In establishing boundaries, factors other than flightpath overshoot that affect the pilot must be considered. Such factors include baseline values of time delay, nonoptimum control gradients, nonlinearities, and pilot training and backyround.

In Fig. 8, the mean trend $1 \mathrm{ine}$ has a $4.0 \mathrm{PR}$ at zero flightpath angle peak overshoot. If this is assumed to be due to factors other than flightpath peak overshoot, the trend line must be shifted upward to correct for these other factors. Ideally, this correction could be implemented by shifting the mean trend line up to 1.0 PR at the origin. However, as all aircraft are less than perfect, a conservative approach would be to shift up to 2.0 PR to allow for some interaction between flightpath overshoot effects and other vehicle characteristics. This approach is illustrated in Fig. 9. The resulting flying quality boundaries for flightpath angle peak overshoot, expressed in round numbers, are 40 percent for level I boundary; 100 percent, level II; and 140 percent, level III.6

This proposed criterion is derived from a fairly broad data base from a quantity and variety of configurations point of view. However, the configurations were primarily generic mediumweight transports. Therefore, the effect of airplane class or size has not been factored in. In addition, not all the TIFS large aircraft data were included; only shuttle-like configurations were. More data are needed in the region of 50to 100-percent overshoot to confirm the criterion boundaries. Nevertheless, based on the good results experienced to date and within the restrictions presented here, this criterion is expected to provide useful guidelines for providing good flying qualities during landing.

\section{Concluding Remarks}

An analysis was made of data from four different in-flight simulator programs and one ground simulation program in terms of the flightpath peak overshoot parameter. These data were primarily for a generic transport aircraft. Very good correlation was found between this metric and pilot ratings of the landing task. Based on these results, boundaries were proposed to define values of flightpath peak overshoot required for level I to III flying qualities in the landing task.

\section{References}

1Berthe, C.J., Chalk, C.R., and Sarrafian, S., "Pitch Rate Flight Control Systems In The Flared Landing Task And Design Criteria Development," NASA CR-172491, 0ct. 1984.

2Berry, D.T., "A Flightpath Overshoot Flying Qualities Metric for the Landing Task," NASA TM-86795, Jan. 1986.

3 Weingarten, N.C. and Chalk, C.R., "In-Flight Investigation of Large Aircraft Flying Qualities for Approach and Landing," AFWAL-TR-81-3118, Sept. 1981.

${ }_{\text {Mooij, H.A., Criteria for Low-Speed }}$ Longitudinal Handling Qualities (of Transport Aircraft with Closed-Loop Flight Control Systems). Martinus Nijhoff Publishers for NLR, Netherlands (U.S. distributor: Kluwer Academic Publishers, Hingham, Mass.), 1985.

5Powers, B.G. and Sarrafian, S.K., "Simulation Studies of Alternate Longitudinal Control Systems for Space Shuttle Orbiter in the Landing Regime," AIAA Paper 86-2127-CP, to be presented at AIAA Atmospheric Flight Mechanics Conference, Willi amsburg, Va., Aug. 18-20, 1986.

6"Military Specification: Flying Qualities of Piloted Airplanes," MIL-F-8785C, ASD/ENESS, Wright-Patterson AFB, Nov. 1980. 

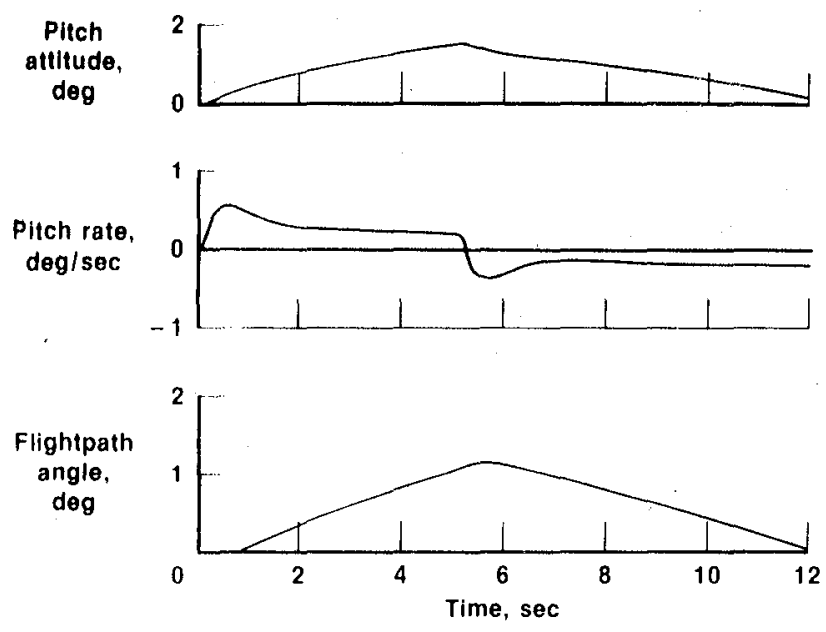

Fig. 1 Typical response for conventional aircraft, 5-sec boxcar command input.
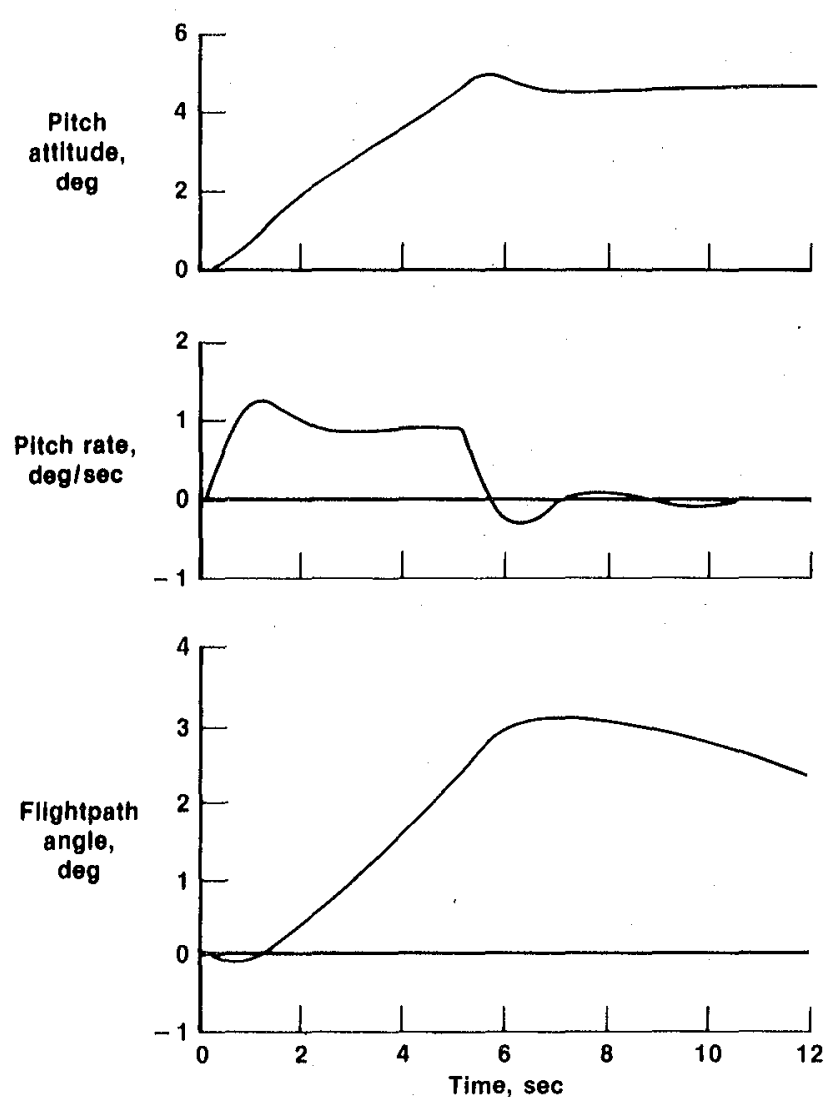

Fig. 2 Typical response for pitch-rate command system, 5-8ec boxcar command input.

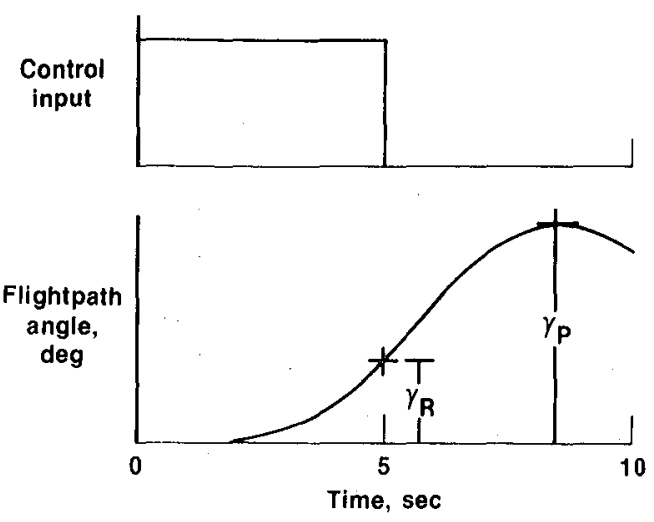

$\gamma$ peak overshoot (percent) $=\frac{\gamma_{P}-\gamma_{\mathbf{R}}}{\gamma_{\mathbf{R}}} 100$

$\gamma_{\mathbf{P}}=$ flightpath angle at peak overshoot, deg

$\gamma_{\mathbf{R}}=$ flightpath angle at control release, deg

Fig. 3 Flightpath angle response features. 


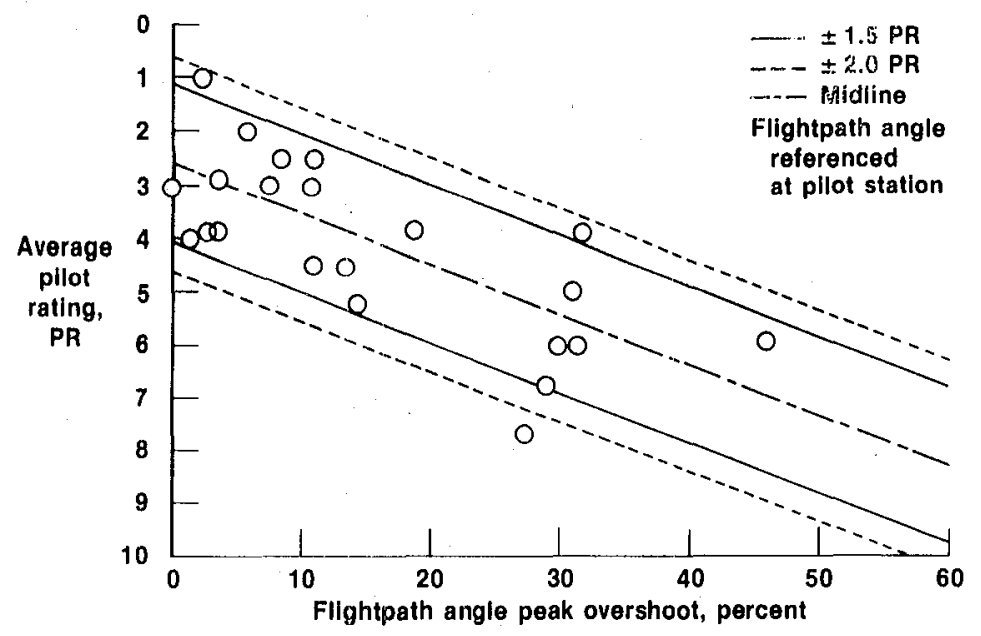

Fig. 4 Average pilot ratings as a function of flightpath angle peak overshoot, TIFS PRCS study.

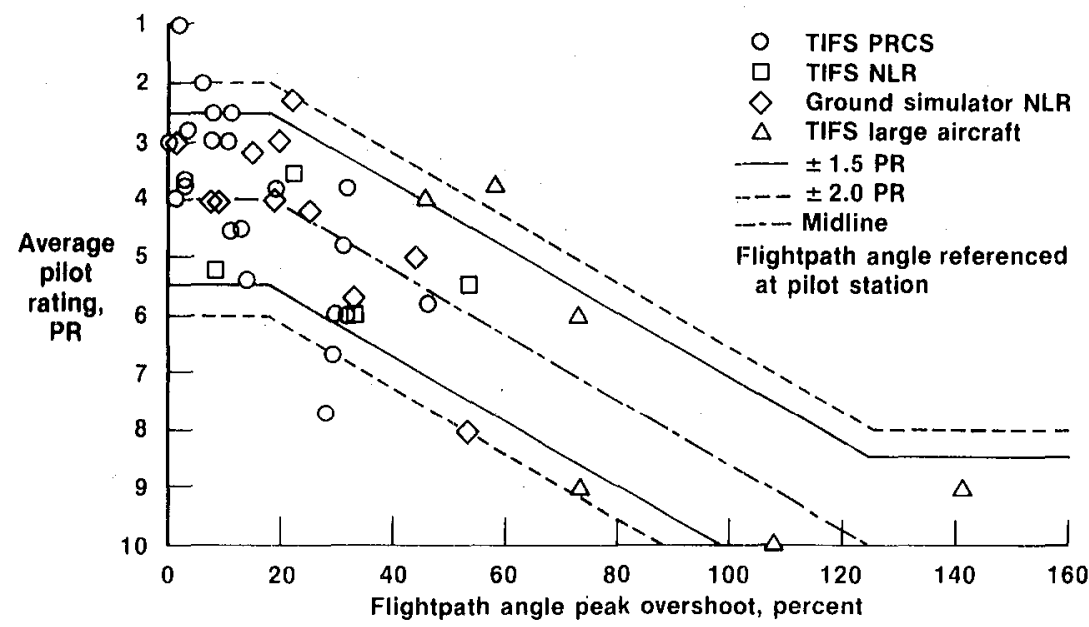

Fig. 5 TIFS PRCS study results with NLR and large aircraft results added.

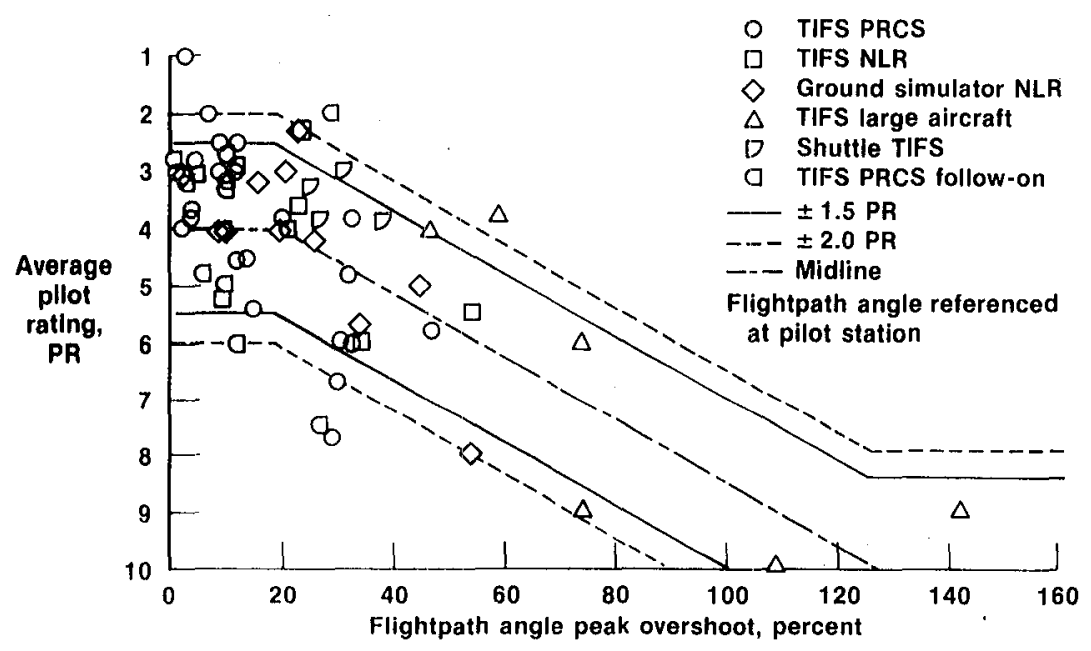

Fig. 6 TIFS PRCS study results with NLR, large aircraft, shuttle, and PRCS follow-on results added. 


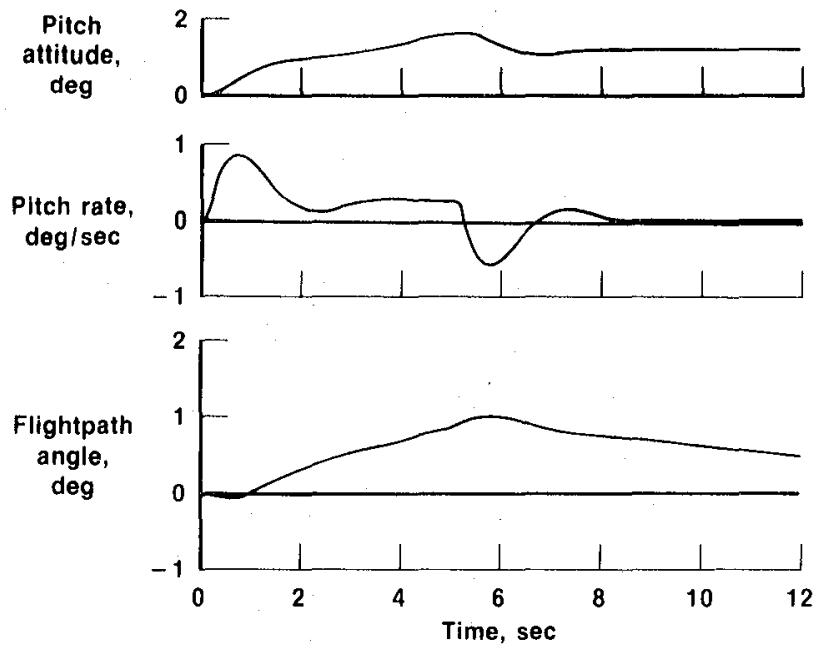

a) Typical aircraft response for pitch-rate command with lead-lag prefilter.
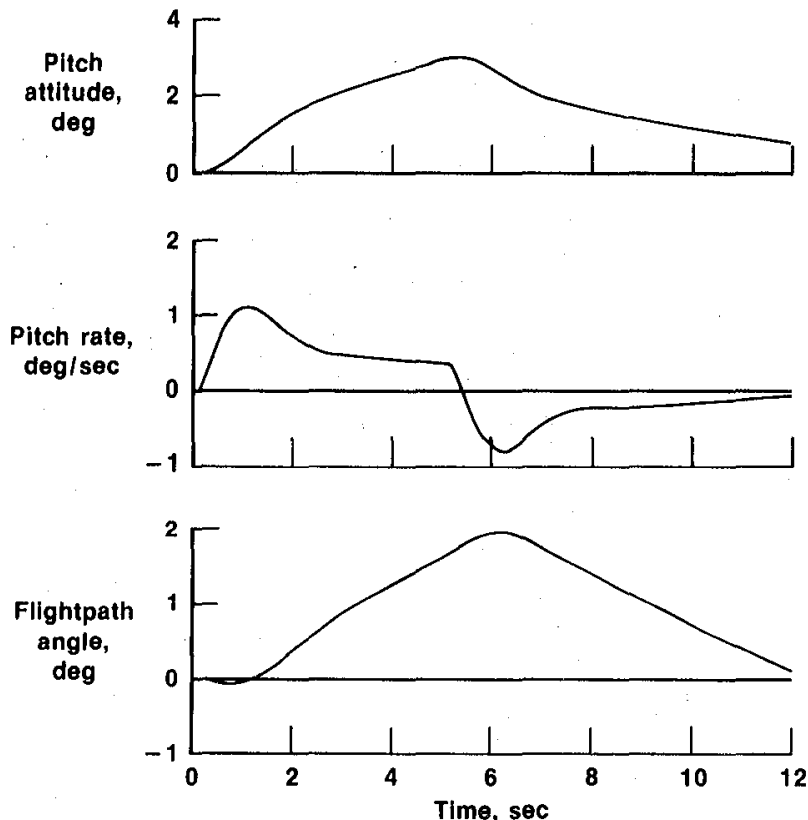

b) Typical aircraft response for pitch-rate command with washout filter.

Fig. 7 Effect of lead-lag and washout on flightpath angle overshoot, 5-8ec boxcar command input. 


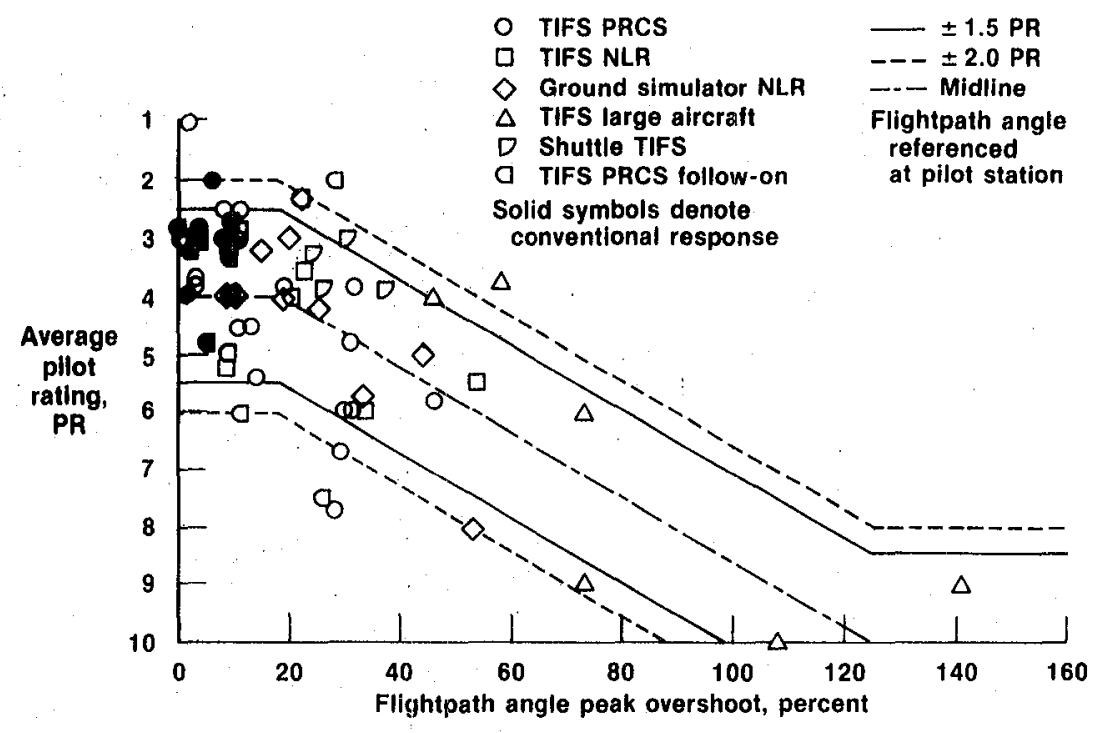

Fig. 8 Combined study results with conventional response configurations emphasized.

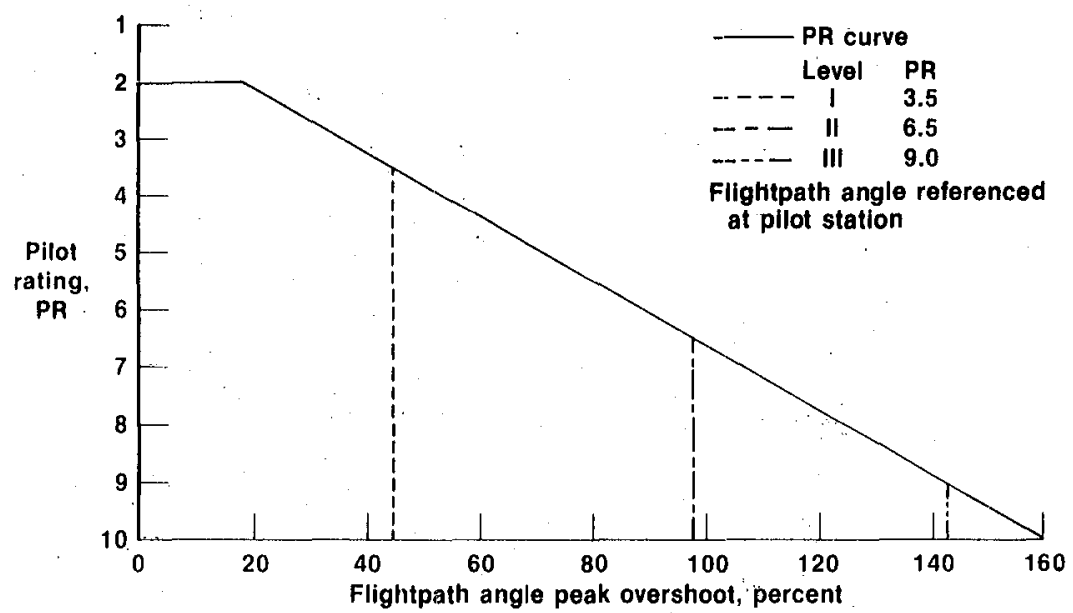

Fig. 9 Flying quality boundaries for flightpath angle peak overshoot. 


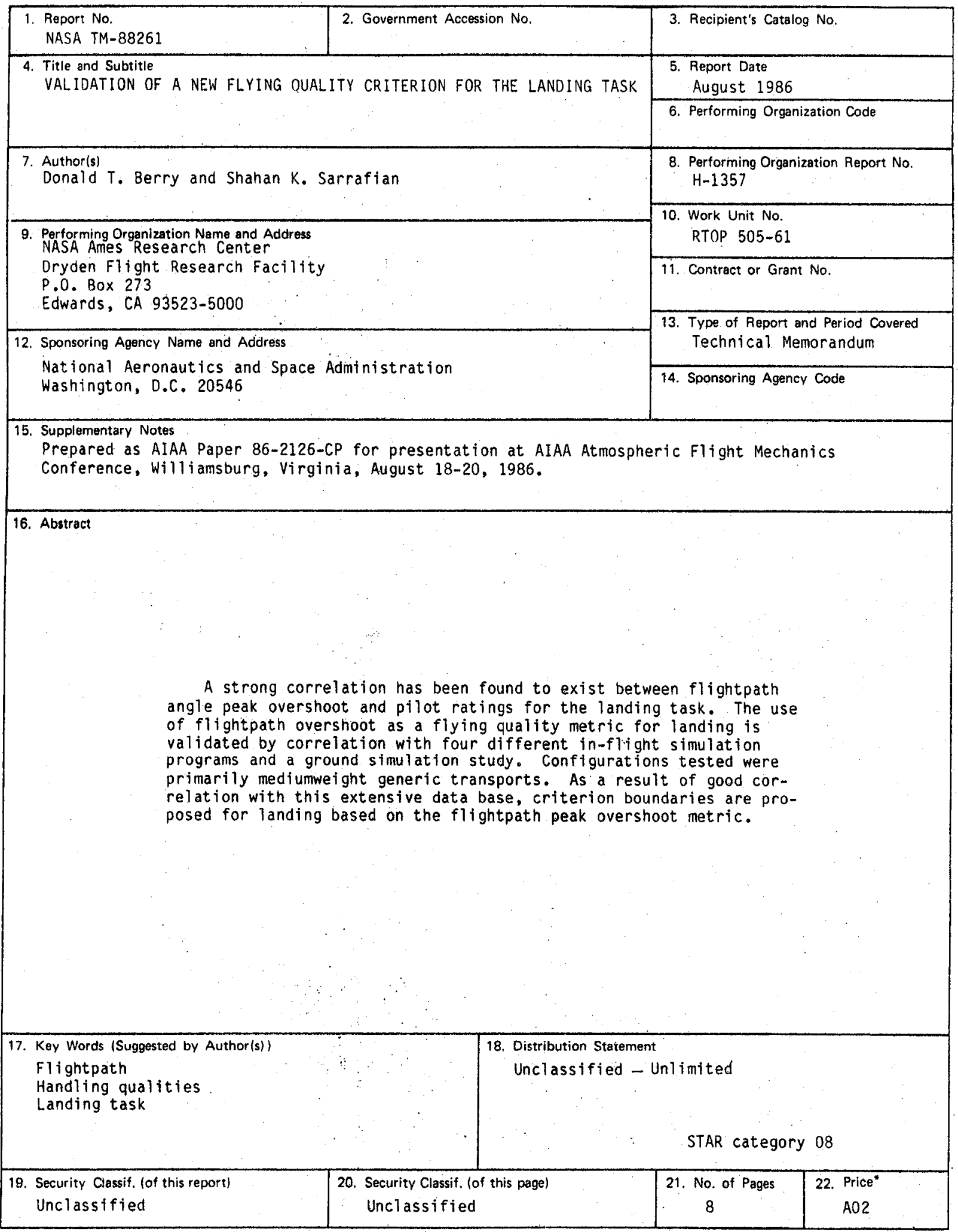

*For sale by the National Technical Information Service, Springfield, Virginia 22161. 
End of Document 